\title{
Hydroxychloroquine efficacy and safety in preventing SARS-CoV-2 infection and COVID-19 disease severity during pregnancy (COVID-Preg): a structured summary of a study protocol for a randomised placebo controlled trial
}

Raquel González ${ }^{1,2,3^{*}+}$ D, Laura García-Otero ${ }^{1,3+}$, Clara Pons-Duran ${ }^{1,2}$, Elena Marbán-Castro ${ }^{1,2}$, Anna Goncé4, Elisa Llurba ${ }^{5}$, Maria del Mar Gil ${ }^{6,7}$, Miguel Ángel Rodríguez-Zambrano ${ }^{8}$, Haily Chen ${ }^{1}$, Máximo Ramírez ${ }^{1}$, Azucena Bardaji ${ }^{1,2,3}$ and Clara Menendez ${ }^{1,2,3}$

\footnotetext{
Abstract

Objectives: The primary objectives of the study are:

1. To assess the effect of hydroxychloroquine (HCQ) in reducing SARS-CoV-2 viral shedding by PCR in infected pregnant women with mild symptoms.

2. To assess the efficacy of HCQ to prevent SARS-CoV-2 infection in pregnant women in contact with an infected or suspected case.

3. To evaluate the effect of HCQ in preventing the development of the COVID-19 disease in asymptomatic SARS-CoV-2-infected pregnant women.

The secondary objectives are:

1. To determine the effect of HCQ on the clinical course and duration of the COVID-19 disease in SARS-CoV-2-infected pregnant women.

2. To determine the impact of HCQ on the risk of hospitalization and mortality of SARS-CoV-2-infected pregnant women.

3. To assess the safety and tolerability of HCQ in pregnant women.

4. To describe the clinical presentation of SARS-CoV-2 infection during pregnancy.

5. To describe the effects of maternal SARS-CoV-2 infection on pregnancy and perinatal outcomes by treatment group. (Continued on next page)
}

\footnotetext{
* Correspondence: raquel.gonzalez@isglobal.org

†'Raquel González and Laura García-Otero contributed equally to this work.

'ISGlobal, Hospital Clínic-Universitat de Barcelona, Barcelona, Spain

${ }^{2}$ Consorcio de Investigación Biomédica en Red de Epidemiología y Salud

Pública (CIBERESP), Barcelona, Spain

Full list of author information is available at the end of the article
}

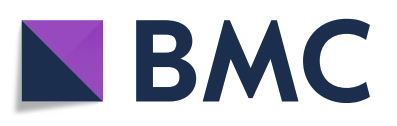

(- The Author(s). 2020 Open Access This article is licensed under a Creative Commons Attribution 4.0 International License, which permits use, sharing, adaptation, distribution and reproduction in any medium or format, as long as you give appropriate credit to the original author(s) and the source, provide a link to the Creative Commons licence, and indicate if changes were made. The images or other third party material in this article are included in the article's Creative Commons licence, unless indicated otherwise in a credit line to the material. If material is not included in the article's Creative Commons licence and your intended use is not permitted by statutory regulation or exceeds the permitted use, you will need to obtain permission directly from the copyright holder. To view a copy of this licence, visit http://creativecommons.org/licenses/by/4.0/ The Creative Commons Public Domain Dedication waiver (http://creativecommons.org/publicdomain/zero/1.0/) applies to the data made available in this article, unless otherwise stated in a credit line to the data. 
(Continued from previous page)

6. To determine the risk of vertical transmission (intra-utero and intra-partum) of SARS-CoV-2.

Trial design: Randomized double-blind placebo-controlled two-arm multicentre clinical trial to evaluate the safety and efficacy of HCQ to prevent and/or minimize SARS-CoV-2 infection during pregnancy. Participants will be randomized to receive a 14-day oral treatment course of HCQ or placebo, ratio 1:1.

Participants: Study population: pregnant women undergoing routine prenatal follow up or attending emergency units at the participating hospitals who report either symptoms/signs suggestive of COVID-19 disease or close contact with a suspected or confirmed COVID-19 case.

Inclusion criteria

Women will be invited to participate in the trial and sign an informed consent if they meet the following inclusion criteria.

- Presenting with fever $\left(\geq 37.5^{\circ} \mathrm{C}\right)$ and/or one mild symptom suggestive of COVID-19 disease (cough, dyspnoea, chills, odynophagia, diarrhoea, muscle pain, anosmia, dysgeusia, headache) OR being contact* of a SARS-CoV-2 confirmed or suspected case in the past 14 days

- More than 12 weeks of gestation (dated by ultrasonography)

- Agreement to deliver in the study hospitals

Exclusion criteria

- Known hypersensitivity to HCQ or other 4-amonoquinoline compounds

- History of retinopathy of any aetiology

- Concomitant use of digoxin, cyclosporine, cimetidine

- Known liver disease

- Clinical history of cardiac pathology including known long QT syndrome

- Unable to cooperate with the requirements of the study

- Participating in other intervention studies

- Delivery onset (characterized by painful uterine contractions and variable changes of the cervix, including some degree of effacement and slower progression of dilatation up to $5 \mathrm{~cm}$ for first and subsequent labours)

The study participants will be stratified by clinical presentation and SARS-CoV-2 PCR results. Assignment of participants to study groups will be as follows:

- SARS-CoV-2-PCR confirmed, infected pregnant women:

a. symptomatic $(\mathrm{n}=100)$

b. asymptomatic $(\mathrm{n}=100)$

- SARS-CoV-2 PCR negative pregnant women in contact* with a SARS-CoV-2-infected confirmed or suspected case $(\mathrm{n}=514)$.

*The ECDC definition of close contact will be followed.

The trial will be conducted in five hospitals in Spain: Hospital Clínic of Barcelona, Hospital Sant Joan de Déu and Hospital de la Santa Creu i Sant Pau, in Barcelona, and HM Puerta del Sur and Hospital Universitario de Torrejón, in Madrid.

Intervention and comparator: Participants will be randomized to HCQ (400 mg/day for three days, followed by 200 mg/day for 11 days) or placebo (2 tablets for three days, followed by one tablet for 11 days).

Main outcomes: The primary outcome is the number of PCR-confirmed infected pregnant women assessed from collected nasopharyngeal and oropharyngeal swabs at day 21 after treatment start (one week after treatment is completed).

Randomisation: Allocation of participants to study arms will be done centrally by the trial's Sponsor (the Barcelona Institute for Global Health, ISGlobal) by block randomization. This method will ensure balanced allocation to both arms. The electronic CRF will automatically assign a study number to each participant, depending on her study group and recruitment site. Each number will be related to a treatment number, which assigns them to one of the study arms.

Blinding (masking): Participants, caregivers, investigators and those assessing the outcomes will be blinded to group assignment. Study tablets (HCQ and placebo) will be identically packaged in small opaque bottles.

(Continued on next page) 


\section{(Continued from previous page)}

Numbers to be randomised (sample size): This study requires 200 SARS-CoV-2 infected and 514 contact pregnant women, randomised 1:1 with 100 and 227 respectively in each study arm.

Trial Status: Protocol version 1.0, from May $8^{\text {th }}, 2020$. Recruitment is ongoing (first patient recruited the $19^{\text {th }}$ May 2020 and recruitment end anticipated by December 2020).

Trial registration: EudraCT number: 2020-001587-29, registered 2 April 2020.

Clinicaltrials.gov identifier: NCT04410562, retrospectively registered 1 June 2020.

Full protocol: The full protocol is attached as an additional file, accessible from the Trials website (Additional file 1). In the interest in expediting dissemination of this material, the familiar formatting has been eliminated; this Letter serves as a summary of the key elements of the full protocol.

Keywords: COVID-19, Randomised controlled trial, Protocol, Hydroxychloroquine, Pregnant, Women

\section{Supplementary information}

Supplementary information accompanies this paper at https://doi.org/10. 1186/s13063-020-04557-y.

Additional file 1. Full Study Protocol

\section{Acknowledgements}

Llorenç Quintó, Xavier Carné, Julia del Amo, Josep Brugada, Franco Pagnoni, Ma Angeles Marcos and Luis Bernardo Herrera González for their methodological contributions.

We acknowledge Laboratorios Rubió for donating the study drugs (both hydroxichloroquine and placebo tablets).

\section{Authors' contributions}

CM conceived the study and led the protocol development. RG and LG-O drafted the protocol. CPD and EMB led the development of ICF and CRFs. $A G, E L L, M M G, M A Z, H C, M R$ and $A B$ reviewed the protocol. All authors read and approved the final manuscript.

\section{Funding}

The trial is funded by the Instituto de Salud Carlos III from the Spanish Ministry of Science and Innovation extraordinary research call on SARS-COV-2 and COVID-19. Project code: COV20/286 (approved on April 17 ${ }^{\text {th }}, 2020$ ). The funding body has no role in the design of the study, collection of data and in writing the manuscript.

\section{Availability of data and materials}

All data will be available to the research collaborators. Decision to publish rests solely with the researchers. The full data set will be made publicly available not later than six months after trial completion.

\section{Ethics approval and consent to participate}

On April $2^{\text {nd }}, 2020$, a short trial proposal was approved by the Comité de Ética en Investigación of the Hospital Clínic of Barcelona to allow the start of the clinical trial procedures in the COVID-19 emergency situation (trial code HCB/2020/0382, meeting reference 9/2020_Extraordinària). The full trial protocol was approved as an amendment by the same committee on the ordinary meeting of May $14^{\text {th }}, 2020$.

The clinical trial was authorized by the Spanish Agency of Drugs and Medical Products (AEMPS) on April $8^{\text {th }}, 2020$ (authorization tracking code FEPZKWTD4D), and the agency approved the full protocol on May $22^{\text {nd }}$ 2020 (authorization tracking code FBVJZBZ766).

Informed consent will be obtained from all participants.

\section{Consent for publication}

Not applicable.

\section{Competing interests}

The authors declare that they have no competing interests.

\section{Author details}

${ }^{1}$ ISGlobal, Hospital Clínic-Universitat de Barcelona, Barcelona, Spain.

${ }^{2}$ Consorcio de Investigación Biomédica en Red de Epidemiología y Salud Pública (CIBERESP), Barcelona, Spain. ${ }^{3}$ Manhiça Health Research Center (CISM), Manhiça, Mozambique. ${ }^{4}$ BCNATAL | Barcelona Center for Maternal Fetal and Neonatal Medicine, Hospital Clínic de Barcelona, Barcelona, Spain. ${ }^{5}$ Obstetrics and Gynecology Department, Hospital de la Santa Creu i Sant Pau, Barcelona, Spain. ${ }^{6}$ Obstetrics and Gynecology Department, Hospital Universitario de Torrejón, Torrejón de Ardoz, Madrid, Spain. ${ }^{7}$ School of Medicine, Universidad Francisco de Vitoria, Madrid, Spain. ${ }^{8} \mathrm{HM}$ Puerta del Sur, Móstoles, Madrid, Spain.

Received: 23 June 2020 Accepted: 25 June 2020

Published online: 02 July 2020

\section{Publisher's Note}

Springer Nature remains neutral with regard to jurisdictional claims in published maps and institutional affiliations.

Ready to submit your research? Choose BMC and benefit from:

- fast, convenient online submission

- thorough peer review by experienced researchers in your field

- rapid publication on acceptance

- support for research data, including large and complex data types

- gold Open Access which fosters wider collaboration and increased citations

- maximum visibility for your research: over $100 \mathrm{M}$ website views per year

At BMC, research is always in progress.

Learn more biomedcentral.com/submission 